\title{
THE CONCEPT FOR NUMERICAL DEVELOPMENT OF MODULAR NETWORKS INTEGRATED WITH THE GNSS MEASUREMENTS
}

\author{
Tadeusz Gargula
}

\begin{abstract}
Summary
The paper presents a proposed adjustment algorithm for an integrated method of measuring situational and altitude details, consisting in combining the modular network elements (classical terrestrial measurements) with the GNSS vectors. Satellite measurements are treated as additional observations, strengthening the network structure, or playing the role of binding (tie) elements between the classical modules. The proposed algorithm is based on the idea of total adjustment of all types of observations (terrestrial, satellite) with the intermediary method, according to the least squares procedure. In order to determine the necessary approximate values of the unknowns (coordinates of the points, which are being determined), the GNSS vectors may be used.
\end{abstract}

\section{Keywords}

modular networks • GNSS vectors • integrated networks parametric method

\section{Introduction}

In geodetic practice, it is increasingly often that satellite measurement techniques are used, supported by traditional (classical) methods. This kind of combination proves beneficial in the implementation of various engineering tasks, such as monitoring the condition of objects exposed to displacements and deformations. As an alternative to the classical situational-height measurement (based on centred positions) the so-called modular networks method can be used [Gargula 2003, Regulation 2012], supplemented with GNSS measurements (vectors).

GNSS measurement often turns out to be insufficient (in terms of the accuracy of determinations); it may be so, for instance, in unfavourable terrain conditions (such as low exposure of the object to satellite signals, or obstacles in the form of buildings, trees, etc.). Another reason for the low accuracy of the GNSS measurement results may lie in the way the measured object is related to the reference system. The use of long reference vectors - the order of several dozen kilometres - for instance, when using the 
ASG-EUPOS system [Regulation 2011], may have an adverse effect on the accuracy of the absolute positions (compare: Gargula 2009b, 2010, 2011b) as well as on the internal geometric set of the local measuring network. Therefore, there is a need to apply additional classical measurements (in a sense, acting as control measures), which at the stage of numerical elaboration, and combined with the GNSS vectors, would form an integrated observation system.

A typical modular network consists of elementary modules connected with each other by means of binding (tie) points [Gargula 2009a]. The elementary modules are generated by a set of angular-linear observations obtained on a single pole measurement station. In the classical approach [Gargula 2003], at the stage of numerical elaboration, the set of observations is transformed into a set of coordinates of points, expressed in an arbitrarily defined local system of the given module. In this case, the network adjustment consists in the simultaneous transformation of all modules into the common system (defined by fixed points). This task boils down to the mathematical solution of a system of conditional equations with unknowns (i.e. local transformation parameters for each of the elementary modules - Fig. 1).

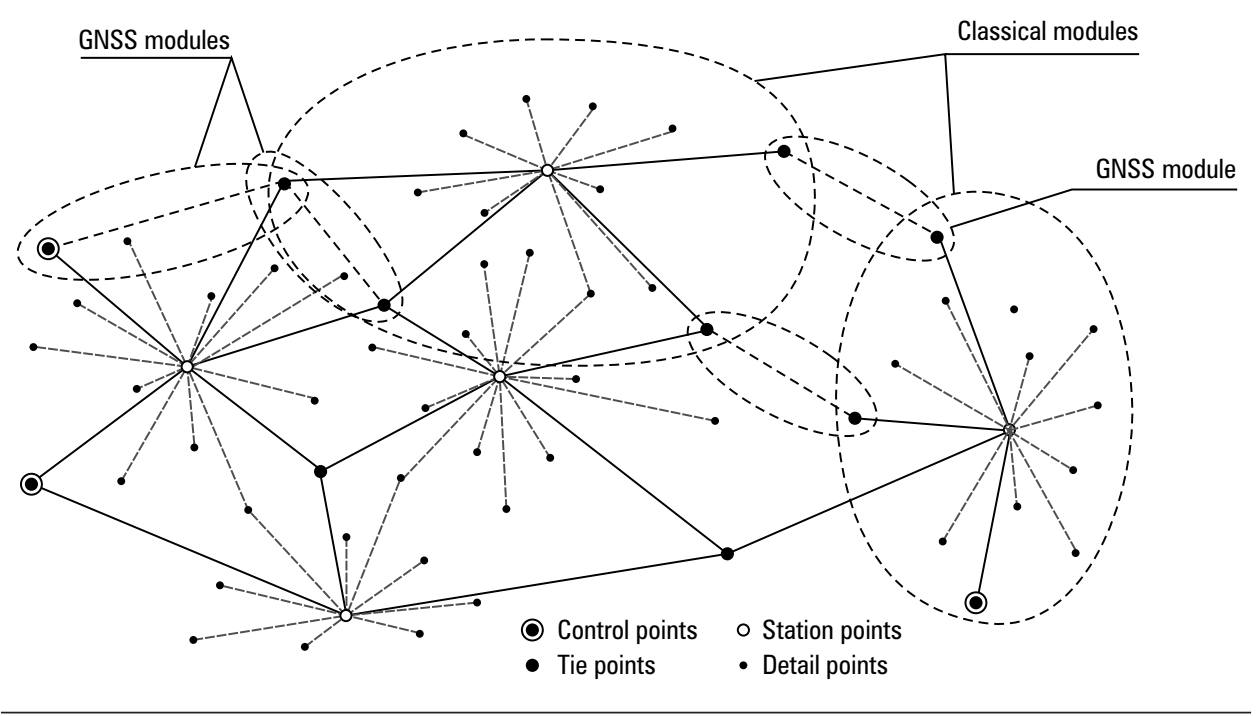

Fig. 1. Structure of a modular network integrated with the GNSS vectors

In the case of modular networks integrated with the GNSS measurements, the elementary module can be formed by the components of the observation vector or by the coordinates of a pair of points of this vector (Fig. 1), expressed in a local system. The GNSS vectors strengthen the network structure (as additional supernumerary observations), and they also enable easy determination of approximate coordinates for the network points, which are being designated. This in turn allows the development of the network using the parametric method, commonly used in the creation of compu- 
tational algorithms in computer programming. The classical observations (angles, lengths) and components of the GNSS vectors will be subjected to adjustment (for instance, after they are projected to the cartographic system). Within the structure of a geodetic network, the GNSS modules (vectors) can also constitute binding elements between classical modules.

The numerical elaboration presented in this paper is an alternative to transformational adjustment. This method (adjustment of modular networks integrated with the GNSS vectors) has already been proposed in an earlier work [Gargula 2003].

\section{Mathematical model for the adjustment of an integrated network}

Needless to say, adjustment of any geodetic network using the parametric method boils down to solving the system of linear correction equations according to the principle of the least squares. In the case of modular networks integrated with GNSS vectors, considered herein, several types of equations will appear in the system of observational equations (Fig. 2). In a three-dimensional space, these will be equations formulated for: 1) slope distance, 2) horizontal angle, 3) vertical angle, and 4) three components of the GNSS vector. In turn, in the observation system of a flat network (adjusted on the plane of the cartographic system) there will be no vertical angle, the slope length will be replaced by a reduced length, and the GNSS vector will be represented by two components (after making appropriate transformations from the three-dimensional WGS'84 system to the plane of the developed network - compare: Gargula 2011a, 2011b). In the present work, we will consider a more general case, which is adjustment the network in a spatial arrangement. The process of linearization of observation equations in itself has been omitted, while the following formulations already present error formulas in a linear form (see for example: Lazzarini et al. 1990, Lamparski 2001, Czarnecki 2010, Osada 2014).

a)

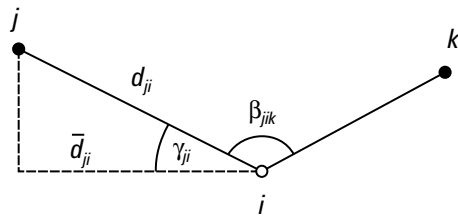

b)

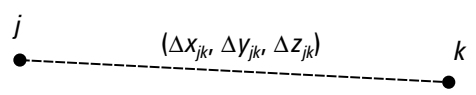

Fig. 2. Elementary observations: a) the classical module; b) the GNSS module ( $i$ - measuring station; $j, k$ - tie points; $\beta$ - horizontal angle; $\gamma$ - vertical angle; $d$ - slope distance; horizontal distance; $\Delta x, \Delta y, \Delta z$ - components of the GNSS vector)

Slope distance

$$
v_{i j}^{(d)}=\frac{\Delta x_{i j}^{(0)}}{d_{i j}}\left(\partial x_{j}-\partial x_{i}\right)+\frac{\Delta y_{i j}^{(0)}}{d_{i j}}\left(\partial y_{j}-\partial y_{i}\right)+\frac{\Delta z_{i j}^{(0)}}{d_{i j}}\left(\partial z_{j}-\partial z_{i}\right)+l_{i j}^{(d)}
$$




$$
\begin{gathered}
l_{i j}^{(d)}=d_{i j}^{(0)}-d_{i j} ; \quad d_{i j}^{(0)}=\sqrt{\left(\Delta x_{i j}^{(0)}\right)^{2}+\left(\Delta y_{i j}^{(0)}\right)^{2}+\left(\Delta z_{i j}^{(0)}\right)^{2}} \\
\Delta x_{i j}^{(0)}=x_{j}^{(0)}-x_{i}^{(0)} ; \quad \Delta y_{i j}^{(0)}=y_{j}^{(0)}-y_{i}^{(0)} ; \quad \Delta z_{i j}^{(0)}=z_{j}^{(0)}-z_{i}^{(0)}
\end{gathered}
$$

where:

$$
\begin{array}{ll}
v^{(d)} & - \text { slope distance correction, } \\
d & - \text { observed slope distance, } \\
d^{(0)} & \text { - approximate slope distance, } \\
(\partial x, \partial y, \partial z) & \text { - coordinate corrections, } \\
l^{(d)} & \text { - free term, } \\
\left(x^{(0)}, y^{(0)}, z^{(0)}\right) & \text { - approximate coordinates, } \\
\left(\Delta x^{(0)}, \Delta y^{(0)}, \Delta z^{(0)}\right) & \text { - increments of the approximate coordinates. }
\end{array}
$$

\section{Vertical angle}

$$
\begin{gathered}
v_{i j}^{(\gamma)}=\frac{\Delta z_{i j}^{(0)} \cdot \Delta x_{i j}^{(0)}}{d_{i j}^{2} \cdot \bar{d}_{i j}^{(0)}}\left(\partial x_{j}-\partial x_{i}\right)+\frac{\Delta z_{i j}^{(0)} \cdot \Delta y_{i j}^{(0)}}{d_{i j}^{2} \cdot \bar{d}_{i j}^{(0)}}\left(\partial y_{j}-\partial y_{i}\right)+\frac{\bar{d}_{i j}^{(0)}}{d_{i j}^{2}}\left(\partial z_{j}-\partial z_{i}\right)+l_{i j}^{(\gamma)} \\
l_{i j}^{(\gamma)}=\gamma_{i j}^{(0)}-\gamma_{i j} ; \quad \gamma_{i j}^{(0)}=\operatorname{arctg}\left(\frac{\Delta z_{i j}^{(0)}}{\bar{d}_{i j}^{(0)}}\right) ; \quad \bar{d}_{i j}^{(0)}=\sqrt{\left(\Delta x_{i j}^{(0)}\right)^{2}+\left(\Delta y_{i j}^{(0)}\right)^{2}}
\end{gathered}
$$

where:

$$
\begin{aligned}
& v^{(\gamma)}-\text { vertical angle correction, } \\
& \gamma-\text { observed vertical angle, } \\
& \gamma^{(0)}-\text { approximate vertical angle, } \\
& l^{(\gamma)}-\text { free term, } \\
& \bar{d}^{(0)}-\text { (approximate) horizontal distance. }
\end{aligned}
$$

\section{Horizontal angle}

$$
\begin{aligned}
v_{j i k}^{(\beta)}= & -\frac{\Delta y_{i k}^{(0)}}{\left(\bar{d}_{i k}^{(0)}\right)^{2}}\left(\partial x_{k}-\partial x_{i}\right)+\frac{\Delta x_{i k}^{(0)}}{\left(\bar{d}_{i k}^{(0)}\right)^{2}}\left(\partial y_{k}-\partial y_{i}\right)+ \\
& +\frac{\Delta y_{i j}^{(0)}}{\left(\bar{d}_{i j}^{(0)}\right)^{2}}\left(\partial x_{j}-\partial x_{i}\right)-\frac{\Delta x_{i j}^{(0)}}{\left(\bar{d}_{i j}^{(0)}\right)^{2}}\left(\partial y_{j}-\partial y_{i}\right)+l_{j i k}^{(\beta)} \\
l_{j i k}^{(\beta)}= & \beta_{j i k}^{(0)}-\beta_{j i k} ; \quad \beta_{j i k}^{(0)}=\operatorname{arctg}\left(\frac{\Delta y_{i k}^{(0)}}{\Delta x_{i k}^{(0)}}\right)-\operatorname{arctg}\left(\frac{\Delta y_{i j}^{(0)}}{\Delta x_{i j}^{(0)}}\right)
\end{aligned}
$$


where:

$v^{(\beta)}$ - horizontal angle correction,

$\beta$ - observed horizontal angle,

$\beta^{(0)}$ - approximate horizontal angle,

$l^{(\beta)}-$ free term.

\section{GNSS Vector}

$$
\begin{gathered}
\left\{\begin{array}{l}
v_{j k}^{(\Delta x)}=\partial x_{k}-\partial x_{j}+l_{j k}^{(\Delta x)} \\
v_{j k}^{(\Delta y)}=\partial y_{k}-\partial y_{j}+l_{j k}^{(\Delta y)} \\
v_{j k}^{(\Delta z)}=\partial z_{k}-\partial z_{j}+l_{j k}^{(\Delta z)}
\end{array}\right. \\
\left\{\begin{array}{l}
l_{j k}^{(\Delta x)}=\Delta x_{j k}^{(0)}-\Delta x_{j k} ; \quad \Delta x_{j k}^{(0)}=x_{k}^{(0)}-x_{j}^{(0)} \\
l_{j k}^{(\Delta y)}=\Delta y_{j k}^{(0)}-\Delta y_{j k} ; \quad \Delta y_{j k}^{(0)}=y_{k}^{(0)}-y_{j}^{(0)} \\
l_{j k}^{(\Delta z)}=\Delta z_{j k}^{(0)}-\Delta z_{j k} ; \quad \Delta z_{j k}^{(0)}=z_{k}^{(0)}-z_{j}^{(0)}
\end{array}\right.
\end{gathered}
$$

where:

$\left(v^{(\Delta x)}, v^{(\Delta y)}, v^{(\Delta z)}\right)$ - the GNSS vector coordinates' increments corrections,

$\left(\Delta x^{(0)}, \Delta y^{(0)}, \Delta z^{(0)}\right)$ - approximate components of the GNSS vector.

\section{Adjustment of the observation system according to the least squares method}

The system composed of all types of correction equations (1), (4), (6), (8) will be recorded as the following matrix:

$$
\begin{gathered}
\mathbf{V}=\mathbf{A} \cdot \mathbf{X}-\mathbf{L} \\
\mathbf{V}=\left[\left\{v_{i j}^{(d)} ; v_{i j}^{(\gamma)} ; v_{j i k}^{(\beta)} ; v_{j k}^{(\Delta x)} ; v_{j k}^{(\Delta y)} ; v_{j k}^{(\Delta z)}\right\}\right]^{T} \\
\mathbf{L}=\left[\left\{l_{i j}^{(d)} ; l_{i j}^{(\gamma)} ; l_{j i k}^{(\beta)} ; l_{j k}^{(\Delta x)} ; l_{j k}^{(\Delta y)} ; l_{j k}^{(\Delta z)}\right\}\right]^{T} \\
\mathbf{X}=\left[\left\{\partial x_{i} ; \partial y_{i} ; \partial z_{i} ; i=1,2, \ldots, p\right\}\right]^{T}
\end{gathered}
$$

where:

A - matrix of coefficients (partial derivatives) at the unknowns (of the point coordinates being determined),

$\mathrm{V}$ - vector of observation corrections,

L - vector of free terms (calculated according to formulas 2, 5, 7, 9, written with the opposite symbol),

$\mathrm{X}$ - vector of unknowns (increments of the approximate coordinates),

$p$ - the number of all designated points. 
The vector of free terms $\mathrm{L}$ appearing in equation (10) can be determined from the difference between two constituent vectors:

$$
\mathbf{L}=\mathbf{L}^{(0)}-\mathbf{L}^{\prime}
$$

$\mathbf{L}^{(0)}$ - vector of approximate (calculated) observations' values,

$\mathrm{L}^{\prime}$ - vector of the observations made (results of measurements).

The vector of observations contains two sub-vectors representing different types of measurements:

$$
\begin{gathered}
\mathbf{L}^{\prime}=\left[\begin{array}{c}
\mathbf{L}^{(\mathrm{K})} \\
\overline{\mathbf{L}^{\mathrm{G}} \overline{)}}
\end{array}\right] \\
\mathbf{L}^{(\mathrm{K})}=\left[\left\{d_{i j} ; \gamma_{i j} ; \beta_{j i k}\right\}\right]^{T} \\
\mathbf{L}^{(\mathrm{G})}=\left[\left\{\mathbf{L}^{(j k)}\right\}\right]^{T} \\
\mathbf{L}^{(j k)}=\left[\begin{array}{c}
\Delta x_{j k} \\
\Delta y_{j k} \\
\Delta z_{j k}
\end{array}\right]
\end{gathered}
$$

where:

$\mathrm{L}^{(\mathrm{K})}$ - vector of the classical observations,

$\mathrm{L}^{(\mathrm{G})}$ - vector of the GNSS observations,

$\mathbf{L}^{(j k)}$ - observation vector for the $j k$ base - of the GNSS vector.

The estimated vector of the unknowns (13) is calculated using the method known from the adjustment calculus (see for example Wiśniewski 2005, Ghilani 2010, Preweda $2013)$, resulting from the imposition on the least squares condition $\left(\mathrm{V}^{\mathrm{T}} \cdot \mathrm{P} \cdot \mathrm{V}=\mathrm{min}\right)$ of the following system of adjustment equations (10):

$$
\begin{gathered}
\widehat{\mathbf{X}}=\left(\mathbf{A}^{\mathrm{T}} \cdot \mathbf{P} \cdot \mathbf{A}\right)^{-1} \mathbf{A}^{\mathrm{T}} \cdot \mathbf{P} \cdot \mathbf{L} \\
\mathbf{P}=\operatorname{diag}\left\{\frac{1}{\left(\mu_{i j}^{(d)}\right)^{2}} ; \frac{1}{\left(\mu_{i j}^{(\gamma)}\right)^{2}} ; \frac{1}{\left(\mu_{j i k}^{(\beta)}\right)^{2}} ; \frac{1}{\left(\mu_{j k}^{(\Delta x)}\right)^{2}} ; \frac{1}{\left(\mu_{j k}^{(\Delta y)}\right)^{2}} ; \frac{1}{\left(\mu_{j k}^{(\Delta z)}\right)^{2}}\right\}
\end{gathered}
$$

where:

P - diagonal matrix of the observation weights,

$\mu^{(d)}, \mu^{(\gamma)}, \mu^{(\beta)}, \mu^{(\Delta x)}, \mu^{(\Delta y)}, \mu^{(\Delta z)}$ - a priori mean errors of individual types of observations (according to Fig. 2). 
The purpose of the adjustment is to determine the observational corrections derived from the equation (10) after substituting the vector $\mathrm{X}$ with the estimated values of the unknowns of the $\mathbf{X}$ vector (19). The next stage consists in combining the adjusted values: the $\mathbf{X}^{(\mathrm{W})}$ coordinates and the $\mathrm{L}^{(\mathrm{W})}$ observations:

$$
\begin{gathered}
\mathbf{X}^{(\mathrm{w})}=\mathbf{X}^{(0)}+\widehat{\mathbf{X}} \\
\mathbf{L}^{(\mathrm{w})}=\mathbf{L}^{\prime}+\mathbf{V} \\
\mathbf{X}^{(0)}=\left[\left\{x_{i}^{(0)} ; y_{i}^{(0)} ; z_{i}^{(0)} ; i=1,2, \ldots, p\right\}\right]^{T}
\end{gathered}
$$

where: $\mathbf{X}^{(0)}$ - the vector of approximate coordinates.

\section{Accuracy assessment (stochastic model)}

The accuracy assessment, carried out after the adjustment, should make it possible to check whether the obtained results meet the requirements of the applicable technical standards. The required criteria for the accuracy of the measurement network determination are the mean errors of the flat coordinates and elevation coordinates, as well as the errors of point positions. These values are easily determined based on the results of network adjustment:

$$
\begin{aligned}
\mathbf{K}=\mu_{0}^{2} \cdot \mathbf{Q} & =\mu_{0}^{2} \cdot\left(\mathbf{A}^{\mathrm{T}} \cdot \mathbf{P} \cdot \mathbf{A}\right)^{-1} \\
\mu_{0}^{2} & =\frac{\mathbf{V}^{\mathrm{T}} \cdot \mathbf{P} \cdot \mathbf{V}}{r}
\end{aligned}
$$

where:

Q, K - respectively: the theoretical and the practical covariance matrix of the vector of unknown values,

$\mu_{0} \quad-$ mean unit error of observation,

$r \quad$ - the number of redundant observations.

The information about mean square errors of the coordinates is contained in the diagonal elements of the matrix $\mathbf{K}$ (mean square errors of the coordinates).

As a global indicator of the accuracy of the assumed matrix, the mean (average) value of the point position error is typically used, which can be calculated directly from the covariance matrix of the vector of the unknown values (24) - see for instance Kadaj [1979]:

$$
\mu_{P_{l r}}=\mu_{0} \sqrt{\frac{1}{p} \cdot \operatorname{Tr}(\mathbf{Q})}
$$

where:

$p \quad$ - number of designated network points,

$\operatorname{Tr}(\mathrm{Q})$ - the trace of the covariance matrix of the vector of the unknown values. 


\section{Conclusions}

The measurement and calculation methodology for modular networks integrated with the GNSS vectors, considered in this paper, may find an effective application in the measurement of areas with a high degree of density of situation-altitude details, as well as in periodic measurements of displacements or deformations. This applies in particular to cases where the use of other methods (for instance, the RTK GNSS) is either impossible or significantly impeded [Gargula et al. 2005]. The main advantage of modular networks is the flexibility of their construction (stations can be set in any place, whereas tie points serve as target points), as well as the possibility of designing the network directly in the field while measuring the details. The introduction of additional observations - the GNSS vectors - aims to strengthen the network structure and provide coordinates of approximate tie points. In some situations (for instance, with no details to measure), the GNSS vectors can serve as tie elements between the segments of classical modular networks (Fig. 1).

Adjustment of the modular network enhanced with the GNSS vectors is possible according to one of two basic methods. In addition to the parametric procedure presented in this paper, there is a slightly more complex method of adjustment, namely, the transformation method. However, the disadvantage of this second method is the need to create individual modules associated with each measurement station, and to compile conditional equations for each tie point [Gargula 2003]. The intermediary method, on the other hand, requires the estimation of the coordinates of the approximate points that are being determined, which is not a simple task considering the irregular structure of the network. Transformational adjustment of the modular network using the approximation method [Regulation 2012] is a time-consuming and hardly cost-effective process. A simple way of obtaining approximate coordinates can be to apply the GNSS vectors for the pairs of tie points. The next steps of adjusting the integrated network do not differ significantly in relation to the adjustment procedure for the classical network.

In the present work, the formulas for creating a system of observational equations in a three-dimensional space (equations 1-9) have been compiled. After an appropriate transformation of the observations into the cartographic plane, the functional model of the adjustment task will contain only the error equations for horizontal angles (or directions), for horizontal length, and for two components of the GNSS vector ( $\Delta x$, $\Delta y$ ). In the further part of the work, a detailed adjustment procedure was shown, in matrix notation (equations 10-23). The stochastic model (formulas 24-26) is used to evaluate the accuracy of the designated points of the integrated network.

The next stage of research work related to the subject of this paper will be the practical verification of the proposed algorithm, using a real practical example (the measurement of displacements in a landslide area). Positive results of this verification will provide the basis for creating an operational computer software program. 


\section{References}

Czarnecki K. 2010. Geodezja współczesna. Gall, Katowice.

Gargula T. 2003. Algorithm for rigorous adjustment of modular networks. Geodezja i Kartografia, 3, 143-152.

Gargula T. 2009a. The conception of integrated survey networks composed of modular networks and GPS vectors. Survey Review, 41(313), 301-313.

Gargula T. 2009b. Wpływ długich wektorów GPS na dokładność pozycji punktu w zastosowaniu do wyznaczania przemieszczeń terenu. Przegląd Geodezyjny, 8, 10-14.

Gargula T. 2010. Application of a damping function in adjustment of GPS networks with long vectors. Allgemeine Vermessung-Nachrichten, 2, 62-70.

Gargula T. 2011a. GPS Vector Network Adjustment in a Local System of Coordinates Based on Linear-Angular Spatial Pseudo-Observations. Journal of Surveying Engineering, ASCE, 137(2), 60-64.

Gargula T. 2011b. Zintegrowane sieci modularne w zastosowaniu do wyznaczania przemieszczeń. Zeszyty Naukowe Uniwersytetu Rolniczego w Krakowie, 473, ser. Rozprawy, 350.

Gargula T., Lis I., Tatara B. 2005. Ocena możliwości zastosowania techniki RTK GNSS jako metody szczegółowych pomiarów sytuacyjnych. Acta Scientiarum Polonorum, ser. Geodesia et Descriptio Terrarum (Geodezja i Kartografia), 4(2), 47-59.

Ghilani C.D. 2010. Adjustment computations: Spatial data analysis. John Wiley \& Sons. Inc., New Jersey.

Kadaj R. 1979. Dwuetapowa metoda wyrównania poziomych sieci geodezyjnych z podziałem układu na podzbiory. Zeszyty Naukowe AGH w Krakowie, 757(59).

Lamparski J. 2001. NAVSTAR GPS. Od teorii do praktyki. Wydawnictwo Uniwersytetu Warmińsko-Mazurskiego w Olsztynie.

Lazzarini T., Hermanowski A., Gaździcki J., Dobrzycka M., Laudyn I. 1990. Geodezja - geodezyjna osnowa szczegółowa. PPWK, Warszawa-Wrocław.

Osada E. 2014. Geodezja: Teoria i praktyka, t. 1, UxLan, Wrocław.

Preweda E. 2013. Rachunek wyrównawczy - modele statystyczne. Progres, Kraków.

Rozporządzenie Ministra Administracji i Cyfryzacji z dnia 9 listopada 2011 r. w sprawie standardów technicznych wykonywania geodezyjnych pomiarów sytuacyjnych i wysokościowych oraz opracowywania i przekazywania wyników tych pomiarów do państwowego zasobu geodezyjnego i kartograficznego, Dz. U. Nr 263, poz. 1572.

Rozporządzenie Ministra Administracji i Cyfryzacji z dnia 14 lutego 2012 r. w sprawie osnów geodezyjnych, grawimetrycznych i magnetycznych, Dz. U. z dnia 30 marca 2012 r., poz. 352.

Wiśniewski Z. 2005. Rachunek wyrównawczy w geodezji. Wydawnictwo Uniwersytetu Warmińsko-Mazurskiego w Olsztynie.

Dr hab. inż. Tadeusz Gargula

Katedra Geodezji

Uniwersytet Rolniczy w Krakowie

ul. Balicka 253A, 30-198 Kraków

e-mail: rmgargul@cyf-kr.edu.pl

ORCID: https://orcid.org/0000-0003-3109-5922 